\title{
Leitura em língua estrangeira: entre o ensino médio e o vestibular
}

\author{
Gretel Eres Fernández \\ Daniela S. Kawamoto Kanashiro \\ Universidade de São Paulo
}

\section{Resumo}

0 presente estudo parte de uma breve discussão sobre o papel da compreensão leitora em língua estrangeira - espanhol - nos cursos de idiomas, bem como sobre as concepções de leitura que subjazem em alguns documentos oficiais, como no Quadro comum europeu de referência para as línguas: aprendizagem, ensino e avaliação e nos Parâmetros Curriculares Nacionais, tanto para o ensino médio quanto para o ensino fundamental. Num segundo momento, tecem-se comentários acerca de como a compreensão leitora é avaliada em alguns exames de vestibular em língua estrangeira. Nossa hipótese inicial centrava-se na existência de coerência entre as orientações oficiais, o que efetivamente deveria ser valorizado nas aulas de idiomas do ensino médio e o conhecimento exigido dos candidatos nas provas de seleção para ingresso em cursos superiores.

Nossas análises revelaram, entretanto, uma discrepância significativa entre os três pontos tomados como referência: embora as diretrizes postulem que o ensino de idiomas deva valorizar o desenvolvimento da competência comunicativa dos aprendizes, é freqüente a prevalência - seja nas aulas, seja nos exames seletivos - de uma concepção tradicionalista do ensino de línguas estrangeiras, que privilegia o conhecimento lingüístico pautado no domínio da metalinguagem e de regras gramaticais, assim como no conhecimento lexical. A ênfase nesses aspectos gera, como uma de suas conseqüências, a restrição significativa da função da compreensão leitora na medida em que o texto assume a função de um simples pretexto para a aferição dos conhecimentos lingüísticos dos candidatos, o que sugere a necessidade de realizar pesquisas específicas destinadas a detectar as causas das divergências constatadas e a apontar caminhos que possam evitá-las ou, ao menos, minimizá-las.

\section{Palavras-chave}

Leitura - Língua estrangeira - Espanhol - Ensino médio - Vestibular. 


\section{Reading in a foreign language: from secondary education to university admission exams}

Gretel Eres Fernández

Daniela S. Kawamoto Kanashiro

Universidade de São Paulo

Contact:

Gretel Eres Fernández

Faculdade de Educação / USP

Av. da Universidade, 308

05508-040 - São Paulo - SP

e-mail: igmefern@usp.br

\begin{abstract}
The present study starts with a brief discussion about the role of reading comprehension in a foreign language - Spanish - in language courses, and also about the conceptions of reading underlying some of the official documents, such as the Common European Framework of Reference for Languages: Learning, Teaching, Assessment, and the Brazilian National Curriculum Parameters for secondary education and for the fundamental school. After that, a few comments are made with respect to how reading comprehension is being assessed in some of the university admission exams. Our initial hypothesis was centered on the existence of coherence between three aspects: the official guidelines, what was supposed to be encouraged in foreign language classes in secondary education, and the kind of knowledge of a foreign language required from candidates in higher education admission exams.

However, our analyses have revealed a significant discrepancy between those three reference points: although the guidelines stipulate that the teaching of languages must emphasize the development of the student's communication competence, what often prevails - both in the classroom and in admission exams - is a traditionalist perspective of the teaching of foreign languages that privileges the linguistic knowledge based on the command of the metalanguage and of grammatical rules, as well as of lexical knowledge. The emphasis on these aspects has as one of its consequences the significant restriction of the function of reading comprehension, given that the text assumes the role of a mere pretext for the evaluation of the linguistic knowledge of the candidates. This fact suggests the need for specific scientific research aimed at investigating the causes of the observed divergences, and at showing ways of preventing them, or at least minimizing them.
\end{abstract}

\section{Keywords}

Reading - Foreign language - Spanish - Secondary education University admission exams. 
Este trabalho tem por objetivo discorrer, brevemente, acerca da abordagem da compreensão leitora em língua estrangeira. 0 foco centra-se no Quadro comum europeu de referência para as línguas: aprendizagem, ensino e avaliação ${ }^{1}$ - documento elaborado pelo ConseIho da Europa - e nos Parâmetros Curriculares Nacionais, tanto os destinados ao ensino fundamental quanto os relativos ao ensino médio - elaborados por organismos brasileiros.

A partir de algumas considerações presentes nos textos citados sobre a concepção de leitura e o papel que é conferido a essa habilidade lingüística nos cursos de língua estrangeira, pretendeu-se também verificar os pontos convergentes e/ou divergentes e de que forma eles se concretizam - ou não - numa situação real em que a compreensão leitora é avaliada formalmente, como no exame de vestibular.

Embora as orientações presentes nos três textos de base sejam aplicáveis ao ensino e à aprendizagem de qualquer língua estrangeira moderna, a perspectiva de análise e de exemplificação tomou como referência a língua espanhola.

Não resta dúvida de que um assunto tão amplo exigiria pesquisas abrangentes que demandariam tempo e espaço não condizentes com a delimitação deste trabalho. Assim, neste momento, as considerações restringem-se com o propósito de elencar algumas questões gerais sobre a compreensão leitora em língua estrangeira que poderão ser ampliadas e detalhadas em futuros estudos.

\section{A leitura em língua estrangeira e os documentos oficiais}

A compreensão leitora, uma das quatro habilidades lingüisticas consagradas, sempre esteve presente na metodologia de ensino de línguas estrangeiras, ora no centro das atenções, ora num lugar secundário. Assim, o Método Gramática e Tradução ${ }^{2}$ não só se apoiava na leitura de textos para estruturar cursos, aulas e materiais didáticos, mas também a incluía entre seus objetivos de ensino e aprendizagem. 0
Método Direto ${ }^{3}$, por sua vez, embora enfatizasse as habilidades orais, partia muitas vezes da leitura de textos para introduzir vocabulário e a oralidade, via leitura em voz alta.

Os métodos audiolinguais ${ }^{4}$ priorizavam a língua falada, sendo que a compreensão leitora só era incluída nos cursos e materiais quando os aprendizes possuíssem um certo grau de domínio oral, pois se acreditava que a exposição dos alunos à língua escrita, precocemente, prejudicaria seu desempenho na língua falada.

Já os métodos comunicativos ${ }^{5}$, surgidos fundamentalmente a partir da década de 1980 e tão presentes na atualidade, procuram - ao menos do ponto de vista teórico - equilibrar a ênfase entre as habilidades lingüísticas e valorizar o desempenho comunicativo, possibilitando que o aprendiz seja capaz de agir adequadamente em diferentes situações de comunicação. Nesse sentido, a compreensão leitora é apenas um dos elementos necessários para a comunicação e deve ser abordada a partir de contextos comunicativos reais, com

1. Tomou-se como base a versão em espanhol deste documento, disponível em <http://cvc.cervantes.es/obref/marco/>. (Marco Común Europeo de Referencia para las lenguas: aprendizaje, enseñanza y evaluación MCER). Nas menções subseqüentes deste documento, não serão indicadas as páginas, posto não constarem no documento eletrônico consultado. Acessado em 03/12/03.

2. 0 Método Gramática e Tradução, também denominado Tradicional, prevaleceu durante séculos no ensino de línguas estrangeiras. Ainda nos dias atuais é utilizado, em maior ou menor medida, por muitos docentes. Entre seus objetivos estão o conhecimento lingüístico e metalingüístico, a tradução e a versão de textos escritos. Para alcançá-los, apóia-se na língua materna, idioma que também funciona como veículo de comunicação em sala de aula (Sánchez-Pérez, 1997).

3. Esse método, consequiência de estudos e aplicações práticas iniciados no segundo quartel do século XIX, contrapõe-se ao Método Gramática e Tradução, seu predecessor, na medida em que privilegia a língua oral, rejeita a tradução e o conhecimento explícito de regras gramaticais (SánchezPérez, 1997).

4. 0 s métodos de base audiolingual surgem na década de 40 do século passado e apóiam-se em princípios estruturalistas e comportamentalistas. Priorizam, principalmente, a língua oral sobre a escrita e o desenvolvimento de hábitos próprios da língua estrangeira, o que ocorre a partir da repetição de estruturas previamente selecionadas e contextualizadas em diálogos (Sánchez-Pérez, 1997).

5. Os métodos centrados na abordagem comunicativa valorizam tanto 0 surgimento quanto o desenvolvimento da competência comunicativa (Hymes, 1962; 1966) do aprendiz e defendem, entre outros aspectos, que aprender uma língua é "construir no discurso (a partir de contextos sociais concretos e experiências prévias) ações sociais (e culturais) apropriadas" (Almeida Filho, 2005, p. 81). 
propósitos claramente definidos, sem perder de vista a integração dessa habilidade com as demais (ouvir, falar e escrever) e com a competência comunicativa em sentido amplo.

Dentro desse panorama, é possível supor que os documentos que subsidiam o ensino e a aprendizagem das línguas estrangeiras elaborados nas últimas décadas levem em consideração os princípios postulados pelos métodos comunicativos, assim como é igualmente possivel supor que os sistemas avaliativos também os tomem como base. Entretanto, uma rápida revisão dos textos legais vigentes e de algumas provas de seleção deixa entrever que, em alguns deles, esses pressupostos teóricos ficam à margem e, em seu lugar, valorizam-se concepções anteriores, como será resumido a seguir.

\section{A leitura no Quadro comum europeu de referência}

O Quadro comum europeu de referência para as línguas: aprendizagem, ensino e avaliação (daqui em diante Quadro) surgiu no início dos anos 2000 como resultado de diversos estudos realizados ao longo de mais de dez anos na Europa por diversos especialistas, no âmbito do projeto geral de política lingüística do Conselho da Europa. Entre os objetivos desse órgão, encontram-se a unificação de diretrizes para a aprendizagem e o ensino das línguas no contexto europeu; daí que o Quadro seja considerado um documento de consulta fundamental e, justamente por isso, sua divulgação seja ampla ${ }^{6}$.

0 Quadro não possui caráter dogmático e entre seus objetivos figura o de incentivar a reflexão - de professores e alunos - sobre o papel da comunicação e sobre a aprendizagem e o ensino de línguas estrangeiras ${ }^{7}$. Não é seu propósito indicar o método de ensino a ser seguido, contudo, o que se observa ao longo da leitura do documento é um esforço constante por ater-se aos princípios teóricos mais atuais para o ensino de línguas estrangeiras. E é justamente dentro da linha metodológica postulada pelos princípios comunicativos que a leitura é considerada nesse documento.

Assim, a compreensão de textos escritos é encarada como parte da competência comunicativa e está vinculada não só às situações de ensino e aprendizagem, mas também - e principalmente - à função que ela desempenha nas atividades reais que integram as competências gerais do indivíduo ${ }^{8}$. Nessa perspectiva, a compreensão leitora pressupõe, também, a interação entre sujeitos e elementos integrantes da comunicação (nesse caso, leitor, autor, texto, conhecimentos prévios do assunto tratado, relações estabelecidas com outros textos etc.).

Nas situações de ensino e aprendizagem de línguas estrangeiras (LEs) ${ }^{9}$, as atividades voltadas para o desenvolvimento da compreensão leitora podem ocorrer sob a forma de tarefas variadas a serem realizadas pelos aprendizes e, para tanto, estes podem utilizar-se de diferentes estratégias disponíveis para executá-las. Assim, "ler e comentar um texto, completar lacunas, preparar uma apresentação oral, [...] cozinhar seguindo as instruções de uma receita etc." (MCER, capítulo 2 - Enfoque adoptado) são estratégias passíveis de serem utilizadas para obter êxito na leitura. Também é exemplo de atividade dirigida ao desenvolvimento da compreensão leitora a leitura de correspondência ou de manuais. Nesse caso, a produção escrita, a produção oral e a compreensão oral também podem estar presentes, ao lado da interação, no sentido de que o leitor também atua, em muitas ocasiões, como produtor de textos, como nas situações em que o estudante é convidado a discutir com um colega o conteúdo ou a argumentação presente num texto escrito ou naquelas atividades em que o aprendiz deve elaborar uma resposta para um anúncio de emprego

6. MCER, Presentación. Essa e todas as demais citações aqui incluídas são traduções livres do texto original em espanhol.

7. MCER, Notas para el usuario.

8. Incluem-se conhecimentos, habilidades, competência existencial e capacidade para aprender (MCER, capítulo 2 - Enfoque adoptado).

9. Neste trabalho, entende-se língua estrangeira como aquela aprendida em contexto formal de maneira seqüenciada e organizada didaticamente. Distingue-se, pois, de segunda língua, termo reservado para os idiomas adquiridos em contexto de imersão e sem manipulação didática. 
publicado num jornal, por exemplo. Dessa forma, no Quadro, estratégia adquire o sentido de "adoção de uma linha específica de ação com o propósito de maximizar a eficácia” (MCER, capítulo 4 - El uso de la lengua y el usuario o alumno).

No documento em discussão, arrolamse diferentes possibilidades de atividades de compreensão leitora (por exemplo, leitura para obter orientação geral ou específica acerca de um assunto determinado, para seguir instruções, por prazer etc.) assim como vários objetivos que podem ser alcançados a partir da leitura (como para captar a idéia geral, para obter informação específica, para compreensão pormenorizada, para inferir opiniões etc.). Dependendo da atividade proposta e dos objetivos a serem alcançados, poderão entrar em jogo atividades e estratégias de interação oral (conversas e discussões formais e/ou informais, debates, entrevistas, negociações, planejamentos etc.), de interação escrita (intercâmbio de anotações e correspondência, realização de traduções, elaboração de resumos, emprego de paráfrases, realização de anotações, entre outras), assim como estratégias de mediação não verbal e paralingüísticas. Nesses dois últimos casos, faz-se referência aos gestos e às ações que acompanham as atividades lingüísticas (normalmente presentes nas atividades realizadas face a face), como o uso de onomatopéias, efeitos prosódicos (tom e tipo de voz ou duração do som emitido, por exemplo) ou inclusive às características paratextuais como ilustrações, gráficos, tabelas, diagramas, figuras, características tipográficas etc.

Subjacentes à oferta de atividades variadas de compreensão leitora, que pressupõe o estabelecimento de diferentes objetivos, encontram-se os saberes que os aprendizes devem possuir para obter êxito em sua consecução. Entre eles, o Quadro (MCER, capítulo 4 - El uso de la lengua y el usuario o alumno) destaca:

- a percepção do texto escrito (que faz referência às habilidades visuais);

- o reconhecimento da escrita (referente às habilidades ortográficas);
- a identificação da mensagem (relacionada às habilidades lingüísticas);

- a compreensão da mensagem (vinculada às habilidades semânticas);

- a interpretação da mensagem (vinculada às habilidades cognitivas).

Daí que seja possível inferir que a concepção de leitura veiculada no documento não se restrinja, de forma alguma, à simples decodificação do signo lingüístico ou à compreensão isolada de vocábulos ou sintagmas. Antes, o que se torna patente é a definição da compreensão leitora como um processo amplo, abrangente, que vai muito além do reconhecimento das palavras - seja na forma, seja no significado - e que implica, necessária e obrigatoriamente, o domínio de habilidades perceptivas, decodificação, inferência, predição, estabelecimento de relações, entre outros, assim como a adequada utilização de recursos auxiliares como dicionários, gramáticas, meios eletrônicos etc.

Devido precisamente a essa concepção de compreensão leitora é que o Quadro (capítulo 4) atribui um sentido amplo ao termo texto:

[...] qualquer fragmento de língua, seja um enunciado ou uma obra escrita, que os usuários ou alunos recebem, produzem ou dele fazem intercâmbio. Portanto, não pode haver um ato de comunicação mediado pela língua sem que haja um texto; as atividades e os processos são analisados e classificados em função da relação existente entre, por um lado, o usuário ou aluno e qualquer interlocutor ou interlocutores e, por outro lado, o texto, seja visto como um produto acabado, como um artefato, como um objetivo ou como um processo em elaboração.

Conseqüentemente, são classificados como texto (oral e/ou escrito):

[...] declarações e instruções públicas, discursos, conferências, apresentações públicas e sermões, rituais (cerimônias, serviços religiosos formais), peças de teatro, espetáculos, leituras, músicas, 
comentários esportivos, retransmissões de notícias, debates e discussões públicas, diálogos, conversas telefônicas, entrevistas de trabalho, livros, publicações literárias, revistas, jornais, manuais de instruções, livros didáticos, histórias em quadrinhos, charges, catálogos, folhetos, material publicitário, cartazes e sinais públicos, sinais de supermercados e lojas, embalagens e etiquetas de produtos, moedas, formulários e questionários, dicionários, cartas, faxes (comerciais e profissionais), cartas pessoais, redações e exercícios, memorandos, relatórios e trabalhos, anotações, bilhetes e mensagens, bases de dados etc.

Como se pode inferir facilmente, tal amplitude e diversidade ${ }^{10}$ levam a que o trabalho com a compreensão leitora também seja variado e abrangente. É claro que, em função dos objetivos perseguidos em cada momento do processo de ensino e aprendizagem de uma LE, pode-se dar mais ênfase a um ou outro aspecto (competência ortográfica, sociolingüística, pragmática etc.), mas sob nenhum pretexto esses objetivos pontuais e específicos devem constituir-se como plenos ou únicos. É necessário não perder de vista o fato de que os objetivos parciais relacionam-se com os objetivos gerais, vinculados à compreensão, à expressão e à interação, ou seja, à competência comunicativa.

Contudo, o Quadro (capítulo 6 - El aprendizaje y la enseñanza de la lengua) deixa em aberto várias questões relacionadas à presença dos textos nas aulas de LE como, por exemplo:

- o papel que os textos desempenham na aprendizagem e no ensino;

- a relevância de utilizar (ou não) textos autênticos;

- a necessidade de que os alunos processem e produzam textos (orais e escritos).

Explicita-se no documento que cabe aos usuários do Quadro determinar o espaço que os textos (orais e escritos) devem ocupar nos programas curriculares assim como quais atividades didáticas são as mais condizentes com cada situ- ação de ensino e aprendizagem. Ou seja, reforçase o caráter não dogmático do documento.

Se, por um lado, esse é um aspecto positivo, por outro pode levar à repetição de modelos que concebem a leitura superficialmente, ou seja, enfatizando apenas questões lexicais ou gramaticais e ignorando os demais elementos que permitem atingir a compreensão profunda de um texto, isto é, corre-se o risco de deixar à margem o desenvolvimento da compreensão leitora em sentido amplo e, portanto, da competência comunicativa.

Contudo, apesar da liberdade dada aos professores no que concerne à adoção de seus princípios e à sua utilização pragmática, em função das características gerais do documento e do uso que dele vem sendo feito (parâmetro para elaboração de materiais didáticos ou definição de níveis de proficiência, por exemplo), não pode ser ignorada a importância do Quadro, inclusive fora da Europa.

\section{A leitura nos Parâmetros Curriculares Nacionais}

\section{A compreensão leitora no ensino fundamental}

Conforme a nova Lei de Diretrizes e Bases da Educação Nacional (Lei 9394/96), o estudo de uma língua estrangeira moderna torna-se obrigatório a partir da $5^{\text {a }}$ série do ensino fundamental, observando que a escolha da língua (inglês, francês, espanhol ou outra língua estrangeira moderna) deve obedecer às necessidades e às possibilidades da comunidade. Os Parâmetros Curriculares Nacionais (daqui em diante PCNs), bem como o Quadro, não têm caráter dogmático: devem, antes de tudo, provocar reflexões e discussões a respeito da prática pedagógica.

No ensino fundamental, o aprendizado de uma outra língua deve promover a compreensão intercultural, no que diz respeito ao co-

10. Vale lembrar que toda essa variedade de textos autênticos inclui, ainda, o fato de terem sido ou não manipulados didaticamente. 
nhecimento de outras culturas e, conseqüentemente, à "aceitação das diferenças nas maneiras de expressão e de comportamento" (PCN-EF, 1998, p. 37), contribuindo para superar visões etnocêntricas e de xenofobia. Assume também a função interdisciplinar, enfatizando a idéia de que o aprendizado de uma outra língua permite o acesso a um número maior de informações em áreas diversas: linguagem, códigos e suas tecnologias; ciências da natureza, matemática e suas tecnologias; e sociedade, cultura e suas tecnologias" ${ }^{11}$.

Ao tomar como base a visão sociointeracionista, a linguagem é compreendida como prática social. Dessa forma, a partir dela, o aluno pode "compreender e expressar opiniões, valores, sentimentos, informações, oralmente e por escrito" (PCN-EF, 1998, p. 54). Aulas com exclusivos exercícios de cópia e tradução, repetição e textos descontextualizados devem dar lugar ao desenvolvimento de atividades que explorem diferentes recursos (TV, gravador, computador, entre outros) e fontes (jornais, revistas, histórias em quadrinhos, receitas, por exemplo), segundo as possibilidades da escola, a fim de que o aluno se conscientize da existência de vínculos entre o que é estudado e seu entorno social. 0 foco deve estar mais no significado e na relevância da atividade do que no estudo do sistema da língua envolvida, embora ele não esteja descartado.

Essa natureza interacional fica evidente no processo de compreensão leitora em que o receptor procura, a partir das marcas deixadas pelo emissor, entender o texto escrito. Para tanto, são ativados os conhecimentos de mundo, da organização textual e do sistema da língua. 0 documento prevê a compreensão geral de um determinado texto no terceiro ciclo (correspondente às $5^{\text {a }}$ e $6^{\text {a }}$ séries) e geral e detalhada no quarto ciclo ( $7^{\mathrm{a}}$ e $8^{\mathrm{a}}$ séries). Além disso, deve ser privilegiado o conhecimento de mundo e textual que o educando já tem de sua língua materna e depois, de forma gradativa, é importante que se procure desenvolver o conhecimento sistêmico.
Nas atividades de compreensão leitora, sugerem-se três fases: pré-leitura, leitura e pósleitura. Na primeira fase, ocorre a sensibilização do aluno a partir da ativação de seu conhecimento de mundo (exploração da presença de gráficos, mapas, desenhos, títulos, subtítulos etc.), da organização textual (observação da distribuição gráfica - uma receita culinária tem estrutura diferente de um texto jornalístico, por exemplo) e da identificação do texto (autor, data da publicação etc.). Na segunda fase, "o aluno tem de projetar o seu conhecimento de mundo e a organização textual nos elementos sistêmicos do texto" (PCN-EF, 1998, p. 92). Nessa fase, as estratégias de inferência são postas em prática a fim de evitar que o aluno se prenda à necessidade de conhecer todos os itens lexicais. É importante que se faça distinção entre informações centrais e detalhes, conforme os níveis de compreensão previamente estabelecidos. Na última fase, a pós-leitura, os alunos avaliam de forma crítica as idéias do autor. Obviamente, durante todo o processo de leitura, pensa-se e reflete-se sobre o texto. Contudo, segundo os PCNs, é nessa última fase que o aluno vai estabelecer de forma mais concentrada essa interação entre seu mundo e as idéias do autor.

A avaliação da compreensão escrita deve ser um processo integrado e contínuo. 0 professor precisa, portanto, "aconselhar, coordenar, dirigir, liderar, encorajar, animar, estimular, partilhar, aceitar, escutar, respeitar e compreender o aluno" (PCN-EF, 1998, p. 82).

Quanto à compreensão leitora, segundo os PCNs (1998), espera-se que, ao final do ensino fundamental, o aluno seja capaz de:

- demonstrar compreensão geral de tipos de textos variados, apoiada em elementos icônicos (gravuras, tabelas, fotografias, desenhos) e/ou em palavras cognatas;

- selecionar informações específicas do texto;

11. Embora 0 agrupamento das diferentes disciplinas em áreas só figure nos $P C N s$ para o ensino médio (EM), considera-se que tais áreas também estão presentes - mesmo que implicitamente - no EF, daí que se julgue possivel estabelecer as mencionadas relações. 
- demonstrar conhecimento da organização textual por meio do reconhecimento de como a informação é apresentada no texto e dos conectores articuladores do discurso e de sua função como tais;

- demonstrar consciência de que a leitura não é um processo linear que exige o entendimento de cada palavra;

- demonstrar consciência crítica em relação aos objetivos do texto, em relação ao modo como escritores e leitores estão posicionados no mundo social;

- demonstrar conhecimento sistêmico necessário para o nível de conhecimento fixado para o texto.

Assim como no Quadro, pode-se concluir que o processo de leitura é amplo e abrangente e não se prende à decodificação lexical ou ao conhecimento de regras gramaticais. 0 conhecimento sistêmico é desenvolvido de maneira gradual e considerado no processo da leitura, mas vale lembrar que não é o foco exclusivo das aulas de línguas.

\section{A compreensão leitora no ensino médio}

Em 1999, foi publicada a primeira versão dos Parâmetros Curriculares Nacionais para o Ensino Médio (daqui em diante PCN-EM). 0 documento foi elaborado conforme os pressupostos da Lei de Diretrizes e Bases da Educação Nacional (Lei n. 9294/96) e do Parecer n. 15/98 do Conselho Nacional da Educação/Câmara de Educação Básica. Com o objetivo de complementar e adequar os PCN-EM, surgiram os PCN+, em 2002, cujo conteúdo provocou discussões. Segundo informações expressas no site do MEC, Ministério da Educação e do Desporto ${ }^{12}$, o Departamento de Políticas do Ensino Médio realizou cinco seminários regionais, entre outubro e dezembro de 2004, e deveria apresentar um outro documento final, em maio de $2005^{13}$, para consolidar uma proposta de organização curricular para o Ensino Médio.

Como a proposta desse trabalho não é um estudo exaustivo dos documentos, faz-se necessá- rio restringir as considerações às informações gerais sobre o tratamento atribuído à compreensão leitora no ensino de língua estrangeira moderna.

Nos PCN-EM, as diretrizes gerais e orientadoras da proposta curricular estão fundamentadas nas quatro premissas abordadas pela UNESCO: aprender a conhecer, aprender a fazer, aprender a viver e aprender a ser. Nesse documento, fica patente a idéia de uma formação geral no lugar da formação conteudística e academicista. Destacam-se duas palavras: contextualização e interdisciplinaridade. 0 conteúdo a ser desenvolvido no ensino médio deve estar sempre contextualizado e deve-se procurar estabelecer relações com outras áreas do conhecimento. São prioridades o raciocínio e a capacidade para aprender e utilizar os conhecimentos para a resolução de problemas do cotidiano.

As competências e habilidades a serem desenvolvidas em língua estrangeira moderna foram agrupadas, devido a fins unicamente didáticos, uma vez que devem ser desenvolvidas como componentes inter-relacionados e interligados em três eixos: representação e comunicação; investigação e compreensão; e contextualização so-ciocultural. Figuram da seguinte forma no documento (PCN-EM, 1999, p. 143):

Representação e comunicação:

- Escolher o registro adequado à situação na qual se processa a comunicação e o vocábulo que reflita a idéia que pretende comunicar.

- Utilizar mecanismos de coerências e coesão na produção oral e/ou escrita.

- Utilizar estratégias verbais e não verbais para compensar as falhas, favorecer a efetiva comunicação e alcançar o efeito pretendido em situações de produção e leitura.

- Conhecer e usar as línguas estrangeiras modernas como instrumento de acesso a informações a outras culturas e grupos sociais.

12. Disponível em: <http://www.mec.gov.br> Acessado em: 25 de abril de 2005.

13. Até o momento da elaboração deste texto, não foi possível ter acesso ao documento citado. 
Investigação e compreensão:

- Compreender de que forma determinada expressão pode ser interpretada em razão de aspectos sociais e/ou culturais.

- Analisar os recursos expressivos da linguagem verbal, relacionando textos/contextos mediante a natureza, função, organização, estrutura, de acordo com as condições de produção/recepção (intenção, época, local, interlocutores participantes de criação e propagação de idéias e escolhas, tecnologias disponíveis).

Contextualização sociocultural:

- Saber distinguir as variantes lingüísticas.

- Compreender em que medida os enunciados refletem a forma de ser, pensar, agir e sentir de quem os produz.

A partir da proposta para a abordagem e o tratamento das habilidades e competências no ensino de língua estrangeira moderna, segundo os PCN-EM, nota-se que se o domínio de uma outra língua colabora para a integração do educando no mundo globalizado; para que isso de fato possa ocorrer, as antigas aulas de repetição e exploração do conteúdo gramatical devem dar lugar ao desenvolvimento das quatro habilidades lingüísticas (ler, escrever, ouvir e falar), assim como ao desenvolvimento da competência comunicativa. Não há uma habilidade a ser priorizada. Segundo o documento, o princípio geral é "levar o aluno a comunicar-se de maneira adequada em diferentes situações da vida cotidiana” (PCN-EM, 1999, p. 148). 0 material utilizado em sala de aula deverá ser diversificado, constituindo-se de notícias, histórias em quadrinhos, letras de música, filmes, diálogos etc. Além da competência gramatical, ao final dos três anos do ensino médio, deve-se garantir igualmente o domínio dos demais componentes da competência comunicativa, quais sejam: a competência sociolingüística (ou sociocultural), a discursiva e a estratégica.

Nos PCN+, dentro do capítulo Linguagens, códigos e suas tecnologias, com relação ao ensino de língua estrangeira moderna, fica claro que a ênfase do aprendizado no ensino médio deve ser a questão da compreensão de enunciados: "[...] o foco do aprendizado deve centrar-se na função comunicativa, por excelência, visando prioritariamente a leitura e a compreensão de textos verbais orais e escritos [...]" (PCN+, 2002, p. 94). As competências e habilidades também estão estruturadas dentro das três perspectivas: representação e comunicação; investigação e compreensão; e contextualização sociocultural. São elas:

Representação e comunicação:

1) Utilizar linguagens nos três níveis de competência: interativa, gramatical e textual;

2) Ler e interpretar;

3) Colocar-se como protagonista na produção e recepção de texto.

Investigação e compreensão

1) Analisar e interpretar no contexto de interlocução;

2) Reconhecer recursos expressivos das linguagens;

3) Identificar manifestações culturais no eixo temporal, reconhecendo momentos de tradição e de ruptura;

4) Emitir juízo crítico sobre as manifestações culturais;

5) Identificar-se como usuário e interlocutor de linguagens que estruturam uma identidade cultural própria;

6) Analisar metalingüisticamente as diversas linguagens;

7) Aplicar tecnologias da informação em situações relevantes.

\section{Contextualização sociocultural}

1) Usar as diferentes linguagens nos eixos da representação simbólica: expressão, comunicação e informação, nos três níveis de competência;

2 e 3) Analisar as linguagens como geradoras de acordo sociais e como fontes de legitimação desses acordos ${ }^{14}$;

14. Embora o mencionado documento não explicite as razões da junção dos itens 2 e 3 , inferimos que o fato de aparecerem unidos deve-se apenas à praticidade que supõe comentar ambos os pontos simultaneamente. 
4) Identificar a motivação social dos produtos culturais na sua perspectiva sincrônica e diacrônica;

5) Usufruir do patrimônio cultural nacional e internacional;

6) Contextualizar e comparar esse patrimônio, respeitando as visões de mundo nele implícitas;

7) Entender, analisar criticamente e contextualizar a natureza, o uso e o impacto das tecnologias da informação.

Antes de detalhar as habilidades e competências e comentá-las, explicitam-se, de maneira não muito clara, os sentidos atribuídos a alguns termos que se relacionam ao contexto exposto.

Com relação à seleção de conteúdos em Língua Estrangeira Moderna, devido ao número reduzido de aulas, geralmente duas aulas semanais, e à heterogeneidade das classes - no tocante a diferentes estágios de aprendizagem -, sugere-se o desenvolvimento do trabalho a partir de três frentes: leitura e interpretação de textos, aquisição de repertório vocabular e estrutura lingüística.

Mais especificamente sobre língua inglesa, há uma lista de conteúdos referentes à estrutura lingüística, que deve desenvolver-se "segundo o grau progressivo de dificuldades dos textos" (PCN+, 2002, p. 104). Da mesma forma, uma lista de temas também é proposta com relação ao trabalho de aquisição de repertório vocabular. Para tanto, sugere-se uma perspectiva interdisciplinar. No que se refere à leitura e interpretação de textos, espera-se que o professor utilize em sala de aula um material diversificado: "publicitário, jornalístico, narrativo, dissertativo, poético, literário, científico" (PCN+, 2002, p. 106). Segundo o documento:

0 trabalho com textos supõe etapas bem definidas quanto à gradação de dificuldades e à escolha de atividades ligadas à interpretação, à aquisição e à fixação de vocabulário, bem como à estrutura lingüística. (p.107)

Os PCN+ apresentam também as competências abrangentes a serem trabalhadas em lín- gua estrangeira moderna: estratégias para ação, conteúdos estruturadores e trabalho por projetos. Especificamente sobre a exploração de texto, destacam-se as seguintes premissas:

- 0 professor deve escolher textos que propiciem o desenvolvimento das quatro habilidades: ouvir, falar, ler e escrever.

- 0 desenvolvimento do trabalho a partir de temas favorece o aprendizado e a elaboração e execução de projetos interdisciplinares.

- É importante que se desenvolvam técnicas de leitura.

- É tarefa do professor orientar o aluno quanto:

- à identificação das idéias principais;

- ao levantamento das palavras-chave;

- à identificação do tema ou assunto;

- ao trabalho com as palavras-ferramenta e as chamadas 'palavras-transparentes'. ( $\mathrm{PCN}+$, 2002, p. 120)

Embora não mais exista o monopólio lingüístico, uma vez que o texto legal (Lei 9394/96) prevê a possibilidade da escolha de uma língua estrangeira moderna segundo as diferenças e necessidades de cada situação de ensino, nota-se que esse documento enfoca mais diretamente - e poderíamos dizer, de maneira quase exclusiva - a língua inglesa, sobretudo ao prever e especificar determinados conteúdos de estrutura lingüística.

Constata-se, a partir da rápida revisão das propostas contidas tanto nos PCN-EM como nos $\mathrm{PCN}+$, a coincidência de concepção - em sentido amplo - defendida para alguns aspectos, sobretudo no que se refere ao tratamento dado à compreensão leitora ${ }^{15}$. Corrobo-

15. Como já citado inicialmente, existe a previsão de uma nova publicação a fim de consolidar uma proposta de organização curricular para 0 ensino médio. Apesar de, no momento, estarem disponíveis alguns textos preliminares a respeito dos debates sobre esse nível de ensino, não cabe discuti-Ios aqui, dado o foco deste estudo e o fato de tratar-se de uma discussão ainda não concluída no âmbito do MEC. Também em razão de ainda não estarem disponíveis, deixa-se de tecer comentários acerca do conteúdo presente nos novos PCN-Língua Estrangeira-EM que se encontram em fase final de elaboração pelo MEC. 
rando as premissas do Quadro e dos PCNs do ensino fundamental, o trabalho com textos não deve restringir-se ao estudo lexical e sistêmico da língua. Espera-se que o professor desenvolva o trabalho com textos sob uma nova perspectiva a partir da utilização de material diversificado e explore as estratégias de leitura, de forma a levar ao desenvolvimento adequado da habilidade de compreensão leitora e do papel que esta exerce no âmbito da competência comunicativa.

\section{Competência leitora $x$ competência lingüística: os exames de vestibular}

No Brasil, ao longo dos últimos anos e impulsionado pelo Mercosul, cresceu o número de interessados em aprender a língua espanhola e, conseqüentemente, muitas escolas passaram a oferecer cursos desse idioma. Em virtude do crescimento da difusão dessa língua em âmbito educacional e socioeconômico, várias instituições de nível superior passaram a oferecê-la como uma opção para o vestibular, pondo fim ao monolingüismo das provas até então instaurado na maioria das instituições de nível superior.

Para a elaboração desses exames, as diferentes instituições possuem autonomia, de forma que é possivel encontrar tipos variados de provas dependendo dos objetivos propostos e das concepções defendidas. Os modelos mais comuns apresentam questões de múltipla escoIha, ainda que existam provas pautadas no somatório das respostas corretas (nesse tipo de prova, deve-se somar os números de todas as alternativas corretas) e provas com questões de respostas discursivas.

Em quase todas as $\operatorname{provas}^{16}$ - independentemente do modelo de questões proposto -, há a inclusão de um texto (ou mais de um) que deve ser compreendido, interpretado ou simplesmente aí figura como um pretexto para a avaliação do domínio de regras gramaticais ou reconhecimento do vocabulário. Nesse último caso, constata-se que nem sempre existe consonância entre o que é proposto para ser desenvolvido no ensino médio, segundo as concepções dos PCN-EM, e o que é avaliado nos vestibulares.

Se partirmos dos pressupostos que:

1) Segundo os PCN-EF e os PCN-EM, a habilidade de compreender os recursos expressivos da linguagem verbal, relacionando textos/contextos mediante a natureza, função, organização, estrutura, de acordo com as condições de produção/recepção, deve ter sido desenvolvida desde o ensino fundamental até o final do ensino médio e que, dessa forma, é imprescindivel que o indivíduo não seja concebido como um mero decodificador de palavras;

2) A língua estrangeira para os alunos de ensino superior deve, sobretudo, servir de instrumento para que tenham acesso a pesquisas, estudos, enfim à literatura estrangeira, necessária a qualquer estudante de nível superior, independente de sua área de conhecimento;

levanta-se a seguinte problemática: até que ponto a grande maioria dos testes de vestibular mede o que se propõe a medir? Seria de se esperar que tais provas, que tomam por base 0 texto escrito, mantivessem coerência com os princípios mais amplos subjacentes ao domínio da compreensão leitora e presentes nos quatro documentos referidos ou, ao menos, nos três documentos nacionais. Não parece adequado que, em muitos dos exemplos de exames analisados, o foco se restrinja ao conhecimento gramatical - normativo - da língua estrangeira.

Entretanto, ao rever o processo de avaliação e seleção, realizado por meio de provas parceladas e ocasionais, em que um erro pode implicar a exclusão do candidato, revela-se ainda maior a necessidade de contar com um instrumento cuidadosamente preparado que vise muito mais à compreensão que à memorização

16. Tomaram-se como base provas de vestibulares realizados no período de 1998 a 2004 em instituições de ensino superior públicas e privadas de todas as regiões do país. 
de regras. Obviamente, em certos casos, tornase necessário recorrer aos procedimentos gramaticais e lexicais para que não se recaia numa interpretação distorcida e imprecisa do texto. Por outro lado, estudar o texto somente do ponto de vista formal pode distanciar o leitoraprendiz da apreensão de seu sentido global.

Ainda que se levem em consideração questões vinculadas à transferência/interferência do português sobre o espanhol, posto que são línguas que apresentam semelhanças, e que determinadas instituições de nível superior talvez se interessem em avaliar esse conhecimento específico, a preocupação exclusiva ou marcadamente prioritária com os aspectos gramaticais não garante que os alunos aprovados nesses exames sejam capazes de compreender um texto na língua estrangeira. Assim, ficam à margem tanto os princípios defendidos pelos textos legais quanto os pressupostos do que seria conveniente que os futuros estudantes universitários dominassem, uma vez que os cursos superiores, normalmente, exigem várias leituras em outras línguas.

Numa espécie de círculo vicioso, devido ao fato de que muitas instituições de ensino superior continuam avaliando conhecimentos de regras gramaticais e do uso do léxico (como se a língua pudesse ser concebida dessa forma), pode-se inferir que várias escolas assumem, de maneira explícita e geral, a missão de preparar os alunos para essas provas. Essas instituições baseiam-se em estratégias que desenvolvem práticas mecanicistas, de treinamentos e memorização de fórmulas. Ainda que neste momento não haja a disponibilidade de um estudo sobre a forma como os institutos de ensino médio conduzem seus cursos de língua estrangeira, não é descabido afirmar que seu grande objetivo é preparar os alunos para as provas de vestibular, direcionando as aulas para o conhecimento gramatical e lexical, mais que para a competência comunicativa.

Infelizmente, ainda hoje se observa a existência da velha dualidade, a escola que prepara para o trabalho e a escola que prepa- ra para o nível superior, embora a lei não defenda essa separação de propósitos.

Não bastasse isso, grande parte das apostilas preparadas para serem utilizadas nos cursos pré-universitários tem por objetivo maior treinar os estudantes para as provas de vestibular e, portanto, não mantém relações diretas com as premissas norteadoras dos PCNs. Esses materiais, em geral, propõem uma formação conteudística e academicista, apenas. E uma vez mais vale insistir na afirmação de que se tais escolas existem é porque seus materiais dão bons resultados, o que indica que as provas para ingresso nas universidades continuam avaliando conhecimentos de regras lingüísticas nem sempre contextualizados. Com relação à língua estrangeira, o que as instituições de ensino superior esperam de seus candidatos? Que sejam "motoristas da língua ou mecânicos da gramática” (Bagno, 2000, p. 120)?

Apesar de todas as tentativas em dar outro enfoque à compreensão leitora, nota-se que entre o que propõem os documentos oficiais e como ela se faz presente nas aulas do ensino médio e se diz avaliada em muitas provas de vestibular, há uma distância muito grande separando os pontos envolvidos.

\section{Algumas considerações finais}

Constata-se, pois, a discrepância existente - mais uma vez - entre aquilo que é defendido nos documentos oficiais e o que ocorre na prática.

Se, por um lado, a concepção de compreensão leitora veiculada nos quatro documentos brevemente resenhados é ampla e supõe uma concepção de ensino de língua voltada para a interação e para a comunicação em sentido abrangente, por outro, o que se verifica em muitas escolas e em muitos exames de acesso a instituições de ensino superior é a aplicação de modelos tradicionalistas de ensino e reducionistas do que significa possuir um bom domínio da habilidade leitora e dos conhecimentos que implicam essa habilidade. 
Por que os postulados referentes à compreensão leitora, incluídos nos textos oficiais, são praticamente ignorados por muitas escolas e por vários exames de vestibular? Sabe-se que na elaboração de tais textos consideraram-se estudos profundos realizados por especialistas e que refletem, em maior ou menor medida, os princípios e as teorias mais atuais e mais aceitos internacionalmente no que tange ao ensino de línguas estrangeiras, em geral, e ao desenvolvimento da compreensão leitora, em particular. Seria de se esperar, portanto, que eles estivessem presentes nas aulas e nas provas, específicas ou não. A partir do momento em que essa relação de proximidade entre teoria e prática é quase inexistente, justifica-se a indicação da necessidade de estudos que procurem averiguar suas causas e, na medida do possivel, que apontem caminhos que levem a uma aproximação entre os princípios teóricos que se defendem e o que se realiza de fato.

\section{Referências bibliográficas}

ALMEIDA FILHO, J. C. P. de. Lingüística aplicada: ensino de línguas e comunicação. Campinas: Pontes, 2005.

BAGNO, M. Preconceito lingüístico: 0 que é, como se faz. São Paulo: Loyola, 2000.

BRASIL. Ministério da Educação, Secretaria de Educação Média e Tecnológica. Parâmetros Curriculares Nacionais: Ensino Médio. Brasília: MEC, 1999.

BRASIL. Ministério de Educação e Cultura. PCN+ Ensino Médio: orientações educacionais complementares aos Parâmetros Curriculares Nacionais: Linguagens e Códigos e suas Tecnologias. Brasilia: MEC/SEMTEC, 2002.

BRASIL. Ministério de Educação e Cultura. Secretaria de Educação Fundamental. Parâmetros Curriculares Nacionais. $3^{\circ}$ e $4^{\circ}$ Ciclos do Ensino Fundamental: língua estrangeira. Brasília, MEC/SEF, 1998.

Marco Común Europeo de Referencia para las Lenguas: aprendizaje, enseñanza, evaluación. Consejo de Europa. Disponível em $<$ http://cvc.cervantes.es/obref/marco/>.

SÁNCHEZ-PÉREZ, A. Los métodos en la enseñanza de idiomas: evolución histórica y análisis didáctico. Madrid: SGEL, 1997.

Recebido em 19.10.05

Modificado em 07.03.06

Aprovado em 22.06.06

Gretel Eres Fernández é doutora e docente da Faculdade de Educação da USP e co-autora de vários materiais didáticos para 0 ensino da língua espanhola.

Daniela Sayuri Kawamoto Kanashiro é professora de espanhol e mestranda do Programa de Pós-Graduação em Educação da Faculdade de Educação da USP. 